\title{
BOTÁNICA Y ZOOLOGÍA GOETHIANA EN EL JOVEN LACAN. LA MORFOGÉNESIS EN “DE LAS PSICOSIS PARANOICAS EN SUS RELACIONES CON LA PERSONALIDAD" 1
}

\author{
GOETHEAN BOTANY AND ZOOLOGY IN THE YOUNG LACAN: \\ MORPHOGENESIS IN “OF PARANOIAC PSYCHOSES IN THEIR \\ RELATIONSHIPS WITH PERSONALITY”
}

\author{
Manuel Coloma Arenas \\ École Lacanienne de Psychanalyse \\ Dirección, país \\ mcol520@gmail.com
}

\begin{abstract}
RESUMen
La tesis en psiquiatría escrita por Lacan en 1932 pretendía demostrar que la psicosis paranoica es equivalente al desarrollo de la personalidad, volviendo inteligible al delirio por su relación
\end{abstract}

El presente artículo es resultado del primer capítulo de mi tesis doctoral "Botánica, zoología y teratología en el joven Lacan. Las bases animales de los tres registros y los primeros indicios de la no relación sexual", gracias al financiamiento de Becas Conicyt, Doctorado Nacional, Capital humano avanzado y al proyecto Fondecyt de iniciación 11150732 "Dinamismo singular de la relación: elementos para una reconstrucción de la ontología relacional a partir de una teoría de las multiplicidades (Simondon, Deleuze)", cuyo investigador responsable es Cristóbal Durán. 
con la historia afectiva del sujeto. Para esto, ocupó el modelo de la morfogénesis goethiana, que se encuentra esparcida en forma velada a lo largo del texto, operando como una imagen paradigmática, referencia metafórica constante que explica los fenómenos del caso específico que Lacan aborda: su paciente denominada por él Aimée. Veremos cómo el recorrido goethiano de zoología-botánica y retorno a la zoología, justifica el uso lacaniano del tropo de la planta y sus diversas metamorfosis.

Palabras clave: morfogénesis, metamorfosis, psicosis, botánica, zoología.

\begin{abstract}
With his 1932 psychiatry thesis Jacques Lacan intended to demonstrate that paranoiac psychosis is equivalent to the development of the personality, becoming intelligible to delirium because of its relation to the affective history of the subject. To argue his point, he used the Goethian morphogenesis model, which is scattered in veiled forms throughout the text, operating as a paradigmatic image and a constant metaphorical reference that explains the phenomena of the specific case that Lacan addresses: a patient he calls Aimée. This paper shows how the Goethean route through zoology-botany and back to zoology justifies the Lacanian use of the trope of the plant and its various metamorphoses.
\end{abstract}

Keywords: Morphogenesis, Metamorphosis, Psychosis, Botany, Zoology

Recibido: 30/04/2019

Aceptado: 15/01/2020

\title{
I. INTRODUCCIÓN
}

En la introducción a su Metahistoria, Hayden White afirmaba que los tropos no solo permiten caracterizar objetos en diversos tipos de discursos, sino que además vuelven inteligibles procesos por los cuales se aprehenden prefigurativamente "contenidos de experiencia que se resisten a la descripción en prosa clara y racional” (43). Podríamos sostener que algo de este orden se 
presenta en Jacques Lacan y en el uso que le dio a la morfología goethiana. Pero también hay algo de esto cuando nos enfrentamos a la tarea de exponer un uso de este tipo: debemos formar a la vez metáforas que nos permitan entender, para los objetivos de este artículo, de qué manera la visión goethiana se relacionaría con una tesis psiquiátrica; dicho en otros términos, explicar con tropos provenientes de esa misma morfología lo que muchas veces no es explícito en la tesis del joven Lacan. Este método nos permitirá comparar las metamorfosis botánicas y animales con los delirios de una psicosis paranoica en sus relaciones con la personalidad. Cabe decir que no se trata solo de la personalidad de una psicosis paranoica, sino que incluso esta relación se expande a la llamada personalidad normal ${ }^{2}$.

Por otra parte, las investigaciones en historia del psicoanálisis -específicamente sobre Lacan- realizados por Jorge Baños Orellana, nos aportan la siguiente hipótesis: "Todo intento de reconstruir el curso de un pensamiento, de desentrañar de dónde vienen tales o cuales conclusiones suyas, supone el espectro de una novela de formación" ("La novelas" 170). Es por esta razón que ha puesto en relieve el papel determinante que habría tenido Goethe en la construcción de la tesis de 1932 (La novela de Lacan). La función que habría cumplido dicha influencia consistiría en reemplazar una metáfora evolucionista utilizada por el maestro en psiquiatría Gaëtan Gatian de Clérambault, en la que el razonamiento delirante "es, a la sana lógica, lo que un gusano redondo (un anélido) es a un vertebrado" (Baños, "Las novelas" 181). En efecto, ese uso apelaba a la convicción de que el anélido, al ser capaz de repetir solo una estructura a lo largo de su cuerpo y pese a estar sometido ya al sistema nervioso, era una imagen adecuada, en tanto antepasado del vertebrado, para dar cuenta de la manera de pensar en las psicosis afectadas tanto de automatismos como de delirios. El reemplazo metafórico hecho por Lacan en 1932 consiste en lo que para Baños Orellana se

2 Ciertamente, el término normal puede llamar la atención por la problemática que abre. Para los objetivos de este artículo, reenviamos a la definición de personalidad que Lacan nos entrega en su tesis y que contiene tres aspectos: i) un desarrollo biográfico, ii) una concepción de sí mismo y iii) una tensión de relaciones sociales (De la psicosis 39). Hemos de seńalar que ya esta definición pone en cuestión la normalidad, puesto que permite ubicar como un fenómeno de personalidad de pleno derecho a la psicosis. 
condensa en la siguiente hipótesis: "así como la imagen de G. De Clérambault es una apropiación de la teoría de Dohrn, Lacan apropia la suya de un libro de Goethe, La metamorfosis de las plantas" (185).

Por nuestra parte, lo que intentamos es profundizar no solo en la morfogénesis que Goethe enseña con la metamorfosis botánica, sino también destacar las relaciones que establece con sus investigaciones zoológicas. Estas exploraciones siguieron un esquema que puede simplificarse cronológicamente como zoología-botánica-zoología. Para no caer en una simple sucesión de intereses, tratamos de mostrar cómo estos estudios disciplinares se imbricaron entre sí, permitiéndonos acceder a una explicación posible de las razones que llevaron a Lacan a preferir una morfogénesis botánica que, sin embargo, no descuida los principios de la zoológica. Y es que la tesis de Lacan contiene efectivamente referencias botánicas y zoológicas -explícitas o latentes-, que sirvieron para el objetivo de incluir "los productos de las psicosis dentro de las potencialidades de lo humano, derribando las fronteras higiénicas de una psiquiatría todavía racionalista” (178). En otros términos, para dar cuenta de un fenómeno propiamente humano como la psicosis -que como veremos, manifiesta en conjunto una condición general de lo humano- había que recurrir no solo a la metáfora de las metamorfosis botánicas y zoológicas, sino también a la metamorfosis inmanente a las metáforas.

\section{El paradigma botánico de Goethe: la morfogénesis}

La relación de Goethe con Freud y el psicoanálisis ha sido estudiada y comentada (Desbordes; Jones). Si bien nos abocamos a un período temprano en Lacan, donde su relación con Freud está empezando y se encuentra lejos de la consigna del retorno, es necesario señalar un rasgo común: el camino de la ciencia médica estuvo para ambos marcado por Goethe, en una mezcla entre poesía y conocimiento científico de la naturaleza. Sabido es que Freud habría decidido inscribirse en medicina al escuchar "Die Natur" (Freud 9), influjo que marcaría la actitud necesaria para llegar a distanciarse de algunos criterios de la profesión escogida. En Lacan, Goethe prestó la 
ayuda necesaria, en términos de influencia intelectual, para producir un viraje desde la neuropsiquiatría al psicoanálisis.

Las dificultades asociadas a un caso de paranoia que no presentaba ni déficit orgánico ni automatismos a la base, volvía necesario contar con un nuevo paradigma. Así, encontramos la presencia de Goethe en la tesis de Lacan a través de dos textos secundarios que remiten a la metamorfosis de las plantas: "Organización y forma en el ámbito de la flor" y "Contribuciones para una visión biológica del mundo" de Wilhelm Troll. Ambos se mencionan en la bibliografía (Lacan, De la psicosis 329), pero las referencias que apelan a la morfología surgen en dos ocasiones a lo largo del texto. Una, a partir del problema del llamado carácter o constitución paranoica, que Lacan aborda considerando el valor problemático ofrecido por las investigaciones caracterológicas, lo que permitiría apreciar, más allá de una constitución jerarquizada, la puesta en juego de la personalidad en las psicosis paranoicas (45-7). Para esto, redacta un párrafo cuyo pie de página incluye la referencia a "Organización y forma..." de Troll, aludiendo a un problema equivalente en ciencias naturales respecto de la jerarquía de los caracteres para decidir cuál es determinante en la estructura y, ante todo, para identificar un carácter que permita establecer algo más que una mera homología formal: "Un mismo carácter estructural, por el contrario, puede presentarse -y ahí está, para demostrarlo, todo el estudio de la morfología- bajo aspectos muy diferentes" (47).

La otra mención la encontramos en un pie de página donde remite, sin explicitar, a la metáfora que ya hemos mencionado utilizada por Clérambault y a la cual Lacan adscribía hasta hacía tan solo un año antes en un texto titulado "Estructura de las psicosis paranoicas" (1931). Esta alusión surge en la tesis a propósito de lo que él llama formas del pensamiento paranoico en el delirio y en la percepción:

Esta impresionante identidad estructural entre los fenómenos elementales del delirio y su organización general impone la referencia analógica al tipo de morfogénesis materializada por la planta. Esta imagen es seguramente más válida que la comparación con el anélido, que nos fuera inspirada, en una 
publicación anterior, por las aproximaciones aventuradas de una enseñanza completamente verbal. (De la psicosis 270)

Para comprender estas apariciones veladas de Goethe revisemos algunos de sus principales postulados morfogenéticos con el objetivo de retomar las citas expuestas en su conexión con el problema ofrecido por las psicosis paranoicas.

La unidad de tipo en los animales y las plantas

Podríamos ubicar en un mismo plano la botánica y la zoología de Goethe, puesto que ambas están atravesadas por un esfuerzo similar donde destaca el concepto de unidad de tipo; en efecto, bajo dicha noción, puede observarse cómo se entrecruzan las investigaciones zoológicas con las botánicas. Así, la Urblatt u hoja primordial fue inspirada por el descubrimiento -llevado a cabo por el mismo Goethe- del hueso intermaxilar en el ser humano. Este evento fue a su vez el resultado de la convicción resultante del siguiente razonamiento: si dicho hueso se encontraba presente en la gran mayoría de los animales, entonces no debía faltar en el humano. En este punto la idea principal de tipo debía funcionar, puesto que Goethe observaba el hecho de que todo animal reconducía a una unidad primaria o modelo original en el que había un intermaxilar. Esta concepción abstracta movió la convicción de Goethe, corroborada empíricamente con el descubrimiento final, en 1784, del intermaxilar humano. Pero lo que empezó en el plano de la zoología tuvo su aplicación más aguda en el campo de la botánica, lugar donde Goethe sostuvo principios que no logró ratificar de modo idéntico cuando, luego de publicar en 1790 "La metamorfosis de las plantas", volvió a sus investigaciones zoológicas, intentando definir la especificidad de la metamorfosis animal.

La hipótesis de este tipo primordial o arquetipo facilitaba la comparación anatómica entre los animales, así como entre estos y el ser humano. Así, el descubrimiento del intermaxilar no solo mostraba una corroboración 
para Goethe de la unidad de tipo, sino también permitía entender las diferentes maneras en que este hueso podía presentarse en cada animal. Si era difícil encontrarlo en el humano, esto se debía precisamente a sus transformaciones y que, pese a las mismas -y por las mismas-, confirman aún más la existencia del modelo primario. El asunto es explicado en "De la existencia de un hueso intermaxilar en la mandíbula superior del hombre al igual que la de los animales" de 1786:

No hay duda de que este hueso se encuentra tanto en el hombre como en los animales, aunque no sea posible determinar sus límites más que de un lado solamente, los otros están soldados y confundidos con los huesos vecinos [...] este hueso, tan prominente en los animales, se retiró hacia atrás, y se redujo a pequeñas dimensiones en el hombre. (Goethe, Oeuvres $84-5)^{3}$

La idea de tipo obliga a pensar que existen órganos comunes cuya variedad según especies se explica por una transformación pesquisable; se encuentran siempre los mismos órganos pero modificados y camuflados. En palabras de von Herder, amigo de Goethe y creyente también de la unidad, el asunto se clarificaba del siguiente modo: "uniformidad de estructura y forma principal, una forma que muta dentro de multitud de variedades [...] de hecho, los miembros principales en sí mismos son formados de acuerdo con un prototipo y varía en casi infinidad de rumbos" (citado en Richards 370). En consecuencia, para Goethe predomina la visión de que las partes distintas en cada uno de los cuerpos de animales y humanos, son mutaciones de una forma primera. Estas mutaciones serían el efecto del impacto del ambiente sobre los cuerpos, el que modifica la forma externa pero siempre en función del material disponible.

Pero la concepción de una forma original o primera, suscita el problema de saber si para Goethe se trataba de encontrar en la experiencia al animal primordial y a la planta primordial. La anécdota entre Goethe y Schiller al respecto es decisiva y se produce en el momento en que Goethe encuentra

La traducción es mía, así como todas las citas de Obras de historia natural. 
un momento para exponerle a su amigo la hipótesis de la metamorfosis de las plantas; al proponerle una imagen - "una planta simbólica” (citado en Cassirer 249)-Schiller dice lo siguiente: "esto no es una experiencia, es una idea”. Ante esta discusión Goethe decidió que debía existir algún puente que relacionara idea y experiencia. Es aquí donde Ernst Cassirer demuestra los alcances que el pensamiento kantiano habría tenido en Goethe: la idea no se opone a la experiencia sino que más bien es un factor de la misma, regulándola y otorgándole unidad (251).

Fue así que Goethe decidió, luego de haber sostenido firmemente la posibilidad de encontrar esta planta primigenia del mismo modo en que había encontrado el hueso intermaxilar, considerarla más bien como un símbolo (252):

Y cuando en el año 1816 envió a Zelter una nueva edición del Ensayo sobre la metamorfosis de las plantas le aconsejó considerar a la obra tan solo simbólicamente y pensar siempre a este respecto en cualquier otro ser viviente que se desarrolla progresivamente a partir de sí mismo. (252-3)

El concepto de símbolo entonces, le permitía conjugar idea con experiencia, a la vez que establecía, de manera kantiana, ciertos límites en el conocimiento de la vida: "Nunca podemos conocer directamente [...] lo verdadero, idéntico con lo divino; lo vemos tan solo en su reflejo, en ejemplos, en símbolos [...] lo divisamos como vida inconceptualizable y no podemos sin embargo renunciar al deseo de conceptualizarlo" (Goethe, citado en Cassirer 255).

Para el ámbito botánico, la Urblatt-hoja primordial- es el fundamento a la Urpflanze, la planta primordial; Goethe lo comenta así en "La metamorfosis de las plantas": "El mismo órgano que se expande en el tallo como hoja y toma las formas más diversas, se contrae luego en el cáliz, vuelve a expandirse en los pétalos, se contrae en los órganos reproductores, y se vuelve a expandir, por último, como fruto" (31). En efecto, la planta no sería otra cosa más que una hoja que progresa o regresa; estilos y estambres, así como los frutos darían cuenta nada más que de una expansión o contracción (23). 
Guiándose por estos principios, será posible observar la consigna todo es hoja, incluso si la naturaleza nos oculta esta condición: "Así, por ejemplo, la cáscara sería simplemente una hoja replegada sobre sí misma y atrofiada en sus márgenes" (24).

La morfología goethiana, se constituye por los tres principios de forma, formación y transformación (Ochoa y Barahona 62). En "La metamorfosis..." quedarán expuestos los tres modos de concebir esta mutación: primero, la metamorfosis regular, también llamada progresiva, observable desde "las primeras hojas del embrión hasta la formación última del fruto" (Goethe 13); esta metamorfosis, al implicar un progreso gradual, es vista por Goethe como una suerte de ascenso en una escala espiritual, desarrollo que a través de las diversas transformaciones de las partes de la planta, alcanzarían "esa cima de la naturaleza que es la reproducción mediante los dos sexos" (13-4). Segundo, la metamorfosis irregular, regresiva, que retrocede en la serie de sus transformaciones y se debilita. Según Goethe, la naturaleza en este caso, en lugar de apuntar hacia su objetivo, disponiendo a las flores a "la obra del amor" (14), "deja a su criatura en un estado indeterminado, delicado [...] internamente débil e inoperante" (14); pero ante todo, lo que resultará de mayor interés es el hecho de que esta metamorfosis, aun cuando implique un retroceso, es capaz de mostrarnos "lo que la metamorfosis regular nos esconde" (14). El carácter irregular de esta metamorfosis, así como el estado indeterminado y débil en el que queda la planta, no le impiden enseñarnos lo que en la metamorfosis regular solo es posible suponer (dicho principio será fundamental en el uso lacaniano de la morfología goethiana). Finalmente, la metamorfosis accidental, concebida así por realizarse desde el exterior, lo que para Goethe equivale a una excrecencia monstruosa. Evidentemente, se refiere a la extraña relación que puede producirse entre una planta y un insecto, contribuyendo en su metamorfosis así como en su reproducción (14).

Para constatar las distintas formas que adquiere la planta Goethe recurre a su interacción con el medio y las fuerzas de la naturaleza, el "impacto de 'los factores direccionales y cíclicos' sobre el arquetipo” (Ochoa y Barahona 63); de este modo, la formación de los órganos se entiende como la suma de fuerzas progresivas dadas por los nutrientes con los procesos de expansión 
y contracción (63). Nuevamente vemos que estos factores pueden ocultar o presentar formas que ya se encuentran de manera virtual en un modelo primario, arquetipo que explica por qué pueden considerarse formas como expresión analógica de otras que a simple vista parecen diferir: todas tienen su anclaje común y, por lo tanto, por muy ocultas que puedan estar sus distintas partes, expresan esa misma ley general, según la cual todo en ellas sería, en rigor, una hoja.

Es tal el alcance que el símbolo del arquetipo parece tener, que Goethe, escribiéndole a Herder en 1787, puede imaginar lo siguiente: "plantas que incluso de no existir podrían hacerlo, no meras imágenes pintorescas, no visiones o ilusiones poéticas, sino organismos dotados de verdad y lógica internas. La misma ley podrá aplicarse a cualquier ser vivo” (citado en Gould 149).

Así, el concepto de fuerzas direccionales en las plantas como aquello que determina sus formas, pudo haber influido en la manera de concebir la adquisición de formas en los animales (Ochoa y Barahona 65). El hueso intermaxilar guió la búsqueda del modelo primario en la botánica y pudo, en determinado momento, fomentar la convicción para encontrar la planta primordial en lo empírico. Pero a la vez, lo adquirido en la botánica sirve para volver sobre el animal, permitiendo un paso a un método empíricotrascendental. De este modo, fue posible para Goethe concebir el Urtier, es decir, el animal originario, concepto o idea de animal (66) a partir del cual se desarrollan las formas de todos los animales, sean de la especie que sean. Un ejemplo de esta concepción es expuesta por Goethe en 1796:

Esto se debe a que se compone de partes idénticas, que se modifican gradualmente, por lo que el conjunto orgánico presenta esta armonía perfecta que nosotros admiramos. Homogéneas en el fondo, ellas parecen no solo heterogéneas sino incluso antagónicas, ya que sus formas, su destino, sus funciones son diferentes. Así, mediante la modificación de órganos similares, la naturaleza puede crear los más diversos sistemas que a veces permanecen visibles, a veces se mezclan y se encuentran. (Oeuvres 78) 
Respecto a la forma animal, Goethe se interesó en la estructura del esqueleto, pues ahí "se nos ha conservado, de manera segura y para la eternidad, el carácter exacto de toda forma” (Teoría 7). La comparación entre fósiles impulsó una vez más la necesidad por encontrar un tipo a partir del cual explicar y medir las convergencias o las divergencias con él: "Y como ya antes había buscado la planta originaria (Urpflanze), así trataba ahora de encontrar el animal originario (Urtier)" (8). Puede observarse que a partir de esta comparación, la hipótesis del tipo adelanta lo que pasará a considerarse bajo el concepto de homología (Ochoa y Barahona 66). En 1790, su "Ensayo sobre la forma animal" establecció la importancia del esqueleto en la búsqueda del tipo unificador, dejando de lado la gran mayoría de los órganos (67). Pero el intermaxilar mostraría todavía su importancia en aras de establecer el tipo, lo que se pone de manifiesto en 1794 en el "Ensayo de una teoría general de los huesos": "el arreglo del intermaxilar entero puede indicarnos cómo es el animal, qué tipo de comida consume, incluso su relación con el medio. Por otro lado, tal hueso, con respecto a los demás, refleja la estructura del animal entero" (67).

Siempre en coincidencia con Kant, Goethe despliega la hipótesis de ciertas condiciones de existencia que se expresan en la llamada Bildungstrieb, (pulsión de formación). Dicho concepto fue acuñado por Blumenbach, quien consiguió así "describir el ámbito y los límites de una esfera de fenómenos en los seres vivos que trascendía la mera reproducción" (citado en Market y Rivera de Rosales 327); finalmente la definió como Lebenskraft (vitalidad) cuyo resultado podemos observar empíricamente manteniendo su causa desconocida. Kant, por su parte, destaca una diferencia entre una fuerza física sometida a las leyes mecánicas (bildende Kraft o Bildungskraft) y la bildungstrieb como expresión de una finalidad del ser viviente, función integradora y refleja ante las fuerzas exteriores (328). Para Goethe, esta Bildungstrieb era concebida como contenido del modelo primordial y, por lo tanto, se trataba de una "fuerza dinámica potencial" (Ochoa y Barahona 69) responsable, en última instancia, del "desarrollo metamórfico del ser" (69). Se trata finalmente, de un juego permanente entre esta fuerza potencial y las fuerzas externas que moldean la configuración final del animal. 
Pero el animal tenía sus límites y el problema de la muerte era lo que generaba dicho obstáculo; si bien era posible notar en él la presencia oculta del animal primordial, la organización más diferenciada que mostraba, tanto en relación con las plantas como con los animales de condición inferior (anélidos, por ejemplo), informaba que, al perder el centro de operaciones implicado por la jerarquía del sistema nervioso, el animal moriría.

De esta manera, si bien Goethe destacaba la presencia de la fuerza formadora en los seres vivientes, se percató de la necesidad de establecer una diferencia entre las transformaciones animales y botánicas. Y es que las plantas podían generar sus partes a partir de un organismo en su totalidad, proceso imposible en el animal (Ochoa y Barahona 71); tanto regresión como progresión, expansión o contracción demostraban que las partes podían constituir el todo:

Compare los organismos inferiores a los organismos más perfectos, usted verá que los primeros, elaborando completamente los cuerpos elementales para apropiárselos, no sabrían elevar los órganos que resultan de eso a este alto grado de perfección y de invariabilidad que se observa en los animales superiores. Así, descendiendo todavía más bajo en la escala de los seres, encontramos las plantas que siguen desarrollándose en una gradación determinada, y nos presentan los mismos órganos bajo las formas más diversas. (Goethe, Leçons 72-73)

Para Goethe esto se debe a la superioridad que adjudica a la condición del animal, puesto que asume una configuración más perfecta en la medida en que los cuerpos están mayormente diferenciados. Incluso los animales considerados imperfectos o inferiores demuestran que ahí no se cumpliría la ley de la regresión o progresión tal como es observable en las plantas: “en los insectos su transformación va primeramente de huevo a oruga y después de oruga a mariposa, pero no a la inversa" (Ochoa y Barahona 71). Esta serie de condiciones y diferencias entre la formación de plantas y animales debieron resultar de interés para la necesidad que Lacan tuvo de contar con una nueva imagen que permitiera explicar las formas del pensamiento paranoide bajo una estructura común. Esta última facultaría reunir delirios 
con automatismos, así como a estas mismas manifestaciones en su relación con la personalidad.

En síntesis, el animal y su metamorfosis presentan ciertos límites que la planta no, debido a que esta puede expresar la totalidad de una estructura en un órgano (un solo órgano repite toda la estructura aunque esta parezca escondida). Sin embargo hemos visto que para Goethe esta característica de la planta constituye una condición de inferioridad respecto de los seres más diferenciados, esto lo obliga a pensar que incluso dentro de los mismos animales hay escalas de seres que podrían considerarse cercanos a este tipo de metamorfosis, convirtiéndolos entonces, en organismos ubicados en la parte baja de la escala animal: "Cuanto más imperfecta es la criatura, tanto más estas partes son iguales entre sí o análogas, y tanto más se asemejan al todo. Cuanto más perfecta sea la criatura, tanto más diferentes serán, en cambio, las partes entre sí” (Teoría de la naturaleza 4). Como intentaremos comprobar ahora, para Lacan la cuestión es al revés; si bien hay enunciados propios de la morfología animal goethiana que sirven a sus propósitos, el carácter extremo de la perspectiva de la metamorfosis de las plantas le aporta una analogía más resuelta para solucionar la disparidad de elementos que se encuentran en el caso Aimée.

\section{Aspectos del caso Aimée explicados con la ayuda de LA MORFOLOGÍA GOETHIANA}

Ubicados en este punto es posible evidenciar una de las primeras utilidades que para Lacan habría tenido la metamorfosis de la planta; en efecto, ¿por qué explicar un fenómeno humano como la locura con un recurso botánico? ¿Es para indicar algún tipo de regresión o de condición de inferioridad? Recordemos que para Goethe -aun cuando podía decir que la palabra Bildung expone "tanto de lo que ya se ha producido, como lo que está en vías de producirse" obligándonos a que "si queremos alcanzar una intuición de lo vivo tenemos que mantenernos flexibles y en movimiento" (4)- la metamorfosis que tenía mayor relevancia, pese a que escondía ciertos hechos, 
era la regular, es decir, aquella que es progresiva y que avanzaba hacia una especie de realización de perfección espiritual (13). Por el contrario, en Lacan vemos que lo que ocurre, al encontrarse con el caso Aimée, no tiene que ver con la idea de un ascenso en las formas, sino más bien con una demostración de similitud en la variedad de estas, según una estructura que no somete a las diferencias a la adquisición de una forma más elevada. Este espíritu se manifiesta al destacar un beneficio positivo de la psicosis (Lacan, De la psicosis 262) que en el caso Aimée, se manifestaba en su imaginación creadora (262-3).

Más allá de las rígidas clasificaciones psiquiátricas que intentan demostrar un déficit asociado a la psicosis, a Lacan le interesa rescatar de la morfología goethiana aquel aspecto bajo el cual la vida es entendida como "proceso y no como producto" (Cassirer 244) y donde no encontramos "formas subsistentes, o sea, formas que no cambian porque han alcanzado ya su perfección, sino que todas fluctúan en un continuo devenir" (Goethe 3). De hecho, es de considerar la exposición que Lacan intenta realizar de lo que podría considerarse como una "estructura conceptual particular que se extiende a las psicosis paranoicas y las psicosis vecinas" (De la psicosis 270) con la ayuda de la morfogénesis de las plantas, la que en este caso, sirve para desplazar la referencia a los anélidos de Clérambault respecto de las relaciones entre "fenómenos elementales del delirio y su organización general" (270), mostrando su "impresionante identidad estructural" (270).

Pero lo que podríamos considerar como una de las mayores consecuencias del material goethiano que Lacan extrae, tal como podemos deducirlo de lo anterior, toca de cerca a la manera en que habría que aproximarse a las psicosis paranoicas en sus relaciones con la personalidad: desligarse de la jerarquía establecida por la perspectiva que aborda la locura con la referencia al sistema nervioso. He aquí el porqué hay algo que no es del todo descartable en lo que Lacan aprende de Clérambault y es que podríamos continuar con la imagen de la repetición indiferenciada del cuerpo anélido - esa analogía extendida y generalizada- a condición de entenderla bajo el modelo de la planta, que no posee sistema nervioso $y$, por ende, no está sometida a sus funciones. Algo de esto se encuentra 
en la zoología de Goethe: aunque el cuerpo animal está mucho más diferenciado, en el nivel de las vértebras se presentaría esa repetición que lo sigue haciendo similar a la metamorfosis de las plantas o incluso de la formación que observamos en los anélidos:

Luego de haber reconocido que la idea de una transformación sucesiva o simultánea de las partes idénticas es la base de todo estudio sobre las plantas o sobre los insectos, nuestras investigaciones sobre los animales serán singularmente facilitadas si suponemos que todos sus órganos sufren una metamorfosis simultánea preparada ya en el momento de la concepción. Es evidente, en efecto, que todas las vértebras son órganos idénticos, y sin embargo quien compare inmediatamente la primera cervical con una vértebra caudal no encontraría trazos de formas análogas. He ahí pues las partes idénticas cuya afinidad es irrecusable, y que son por tanto, muy diferentes; también, al examinar sus conexiones orgánicas, sus puntos de contacto y su influencia recíproca, hemos llegado a un resultado satisfactorio. (Leçons 77)

En otros términos y extendiendo las metáforas, la psicosis paranoica puede ser un anélido, pero a condición de no leer en eso la famosa hipótesis de la filogenia repitiendo la ontogenia, sino más bien a un individuo cuyo sistema nervioso no interviene en lo que es del orden de su pensamiento; dicho de otro modo, para apreciar ese fenómeno humano como lo es la locura, hace falta convertir al humano en planta. Para Lacan, entonces, la palabra humana, tan marcadamente presente en los fenómenos de las psicosis, nos convierte en plantas, o incluso, en animales sin sistema nervioso: pero para esto no hace falta ser psicótico, por el contrario, la psicosis solo pone en evidencia dicha condición general. Entonces, ¿qué nos enseña el caso Aimée?, ¿para qué sirvió específicamente el modelo de la metamorfosis goethiana a la hora de entender las psicosis paranoicas a la luz de este caso?

Lacan propone, no sin reservas, un nuevo tipo clínico, a saber, la paranoia de autocastigo o de autopunición (De la psicosis 243); esta mezcla entre cautela y atrevimiento se observa en el momento en que, antes de 
designar un tipo, resalta la importancia de considerar los casos análogos a partir de un prototipo “que podrá ser 'el caso Aimée' o algún otro" (242). Prefiere la noción de prototipo ya que pone énfasis en no perder de vista, en esos casos análogos, una descripción que tenga en cuenta la especificidad del caso, de manera que sea algo más que una simple síntesis descriptiva a partir de una necesidad de generalización (242). Incluso Lacan tiene consciencia de la dificultad que el término autocastigo puede acarrear, pues supone la objeción de que con dicho concepto no podría demostrarse la anomalía que se intenta describir y, por el contario, se estaría más cerca de mostrar una relación con una función psicológica normal (239). En este punto, aparece nuevamente el deus ex machina del psicoanálisis, específicamente, la noción de libido: "Nosotros sentimos que la evolución de la libido en la doctrina freudiana corresponde con mucha precisión, en nuestras fórmulas, a esa parte (tan considerable para la experiencia) de los fenómenos de la personalidad cuyo fundamento orgánico está dado por el deseo sexual' (239). Así, junto con explicar el caso Aimée como una psicosis que se despliega en forma paralela a la personalidad, la misma se entiende porque se propone una fijación a la etapa libidinal en la que se instala el superyó, coincidiendo con el llamado narcisismo secundario (227). En conjunto, se proponen ciertos acontecimientos que alimentan las ideas delirantes por el hecho de entrar en conexión con el trauma que surge como resultado de la fijación, contribuyendo así a resolver la cuestión en torno a la constitución, aunque con una diferencia relevante en torno a esta "y es que la fijación deja siempre, igualmente, lugar para la hipótesis de un determinismo traumático, detectable históricamente, y evocable subjetivamente mediante una técnica adecuada” (228)

El estadio de génesis del superyó reúne en él, casi en contigüidad, a la fijación narcisista y a la pulsión homosexual, lo que se constituye en otro de los beneficios explicativos de la teoría psicoanalítica de la libido (232). De este modo, Lacan propone el acto de Aimée como un ataque a la imagen a partir de la cual se ha constituido ella misma, imagen de su hermana mayor que por amplificación se convierte en su ideal del yo, permitiendo tanto la sublimación de la pulsión homosexual (232), como su reemplazo 
en una serie de otros personajes femeninos hasta llegar a la actriz atacada (230). La imagen primordial se constituye así en un prototipo al cual todas las demás remiten.

Pero, por otra parte, decíamos que es posible notar en Lacan una lectura del caso Aimée que tiene siempre presente su aspecto móvil e intermedio (241). La solución entonces es el surgimiento de una nueva categoría psiquiátrica que pudiera responder a un caso que parecía tener la facultad de moverse, desplegarse y devenir entre las categorías establecidas por la psiquiatría de la época. Con esto, Lacan explicaba uno de los puntos más llamativos de Aimée, o sea, la curación que daba cuenta de la naturaleza de la enfermedad; en efecto, el autocastigo era un deseo que se cumple no cuando ataca a la actriz, sino cuando comprende que su acto no ha tenido otro resultado que no sea el de recibir, por parte de la sociedad, el castigo legal. En ese momento el delirio cae: "Aimée comprende, entonces, [...] que se ha agredido a sí misma, y paradójicamente solo entonces experimenta el alivio afectivo (llanto) y la caída brusca del delirio, que caracterizan la satisfacción de la obsesión pasional" (235). Y finalmente: "con el mismo golpe que la hace culpable frente a la ley, Aimée se siente golpeada en sí misma: y cuando lo comprende, es cuando experimenta la satisfacción del deseo cumplido: el delirio, ya inútil, se desvanece" (238).

De este modo vemos cumplirse una de las frases más importantes de la primera cita con la que Lacan rinde homenaje a la morfología goethiana: “Un mismo carácter estructural puede presentarse -y ahí está todo el estudio de la morfología- bajo aspectos muy diferentes" (De la psicosis 47). Con Aimée, se trata ahora de establecer similitudes que, a primera vista, parecen inexistentes y para lo cual la metamorfosis de la planta presta un paradigma mucho más correcto que el de los anélidos. Ya no se trata de jerarquías evolutivas, por el contrario, las transformaciones y pasos posibles son entendidos gracias a una estructura única que permite ubicar en su interior fenómenos que sin ella parecían impensables. La intención de Lacan, ya en 1931 con los anélidos de Clérambault y más aún en 1932 con la morfología goethiana, era dar cuenta de una estructura común que uniera las psicosis paranoicas. La diferencia es que en 1932, Lacan no solo 
busca esto, sino que también piensa esta estructura como algo que permite poner en el mismo plano fenómenos que parecían distintos (270).

Las consecuencias de estos enunciados se mantienen a lo largo del tiempo, es una prueba de esto un comentario en su seminario de 1955 sobre "Las psicosis", donde resalta la analogía entre el delirio y el fenómeno elemental al expresar ambos una misma fuerza estructurante tal y como ocurre en la planta (33). El delirio no es deducido, es tan elemental como lo es un automatismo (33). Vemos así uno de los alcances más directos del recurso de la metamorfosis: Goethe, al plantear la existencia de una Urpflanze y que todo es hoja, enunciaba que toda variedad era nada más que un modo de esta unidad propuesta. Aimée podía ser así tanto un prototipo de la paranoia de autocastigo como un paso intermedio entre estados que por la misma razón dejan de ser categorías estancadas.

\section{LA METAMORFOSIS IRREgULAR. ROSAS Y CLAVELES PROLÍfEROS COMO EQUIVALENTES DE LA PSICOSIS Y LA PERSONALIDAD}

Para comprobar lo anterior, resulta de suma importancia volver a comentar la segunda metamorfosis descrita por Goethe y que habíamos dejado en suspenso: la irregular. En ella teníamos dos perspectivas posibles: i) la del estado indeterminado que no alcanza la meta de la reproducción sexuada, dejando a la planta en un estado débil e inoperante, y ii) la metamorfosis irregular que hace aparecer, en su indeterminación, lo que la progresión lograda y regular nos oculta. Sin duda la segunda opción resulta ser la más cercana a lo que nos ofrece el caso Aimée. Así, utilicemos el ejemplo de la llamada rosa proliferante que Goethe menciona en "La metamorfosis" y es que en dicha rosa, la flor no logra frenar el proceso de crecimiento de la planta, expresando así, pese a su enfermedad, la ley general que la gobierna (Baños Orellana, La novela de Lacan 157). Reiniciando entonces el proceso de metamorfosis, esta rosa prolífera logra ser la prueba más ilustrativa del todo es hoja, cuestión que no se observaría tan fácilmente de no ser por su 
condición patológica (157). Conducidos al caso Aimée, podríamos decir que su mal refleja con mayor intensidad una estructura común.

Pero hay algo más, puesto que también las psicosis paranoicas pueden mostrársenos, por su relación con la personalidad y bajo el tipo de crecimiento irregular de las metamorfosis goethianas, como verdaderos claveles prolíferos. En ellos, existe una flor completa

provista, no solo de cáliz, sino también de una doble corola completada en el centro por una cápsula seminal bien determinada, aunque no enteramente desarrollada. De los lados de la corola se desarrollan cuatro nuevas flores completas, separadas de la flor-madre por tallos de tres o más nudos. (Goethe, "La metamorfosis" 28)

Es un caso más extremo aún que el de la rosa, puesto que en el clavel se desarrolla cierta perfección que testimonia el proceso de metamorfosis que continúa su camino incluso habiendo logrado lo que supuestamente era su meta. Esto demostraría que no es tanto el logro de un determinado estado lo que la metamorfosis persigue, sino que, al parecer, solo buscaría continuar su proceso, mostrando que por debajo y sutilmente, marca la pauta de lo que en apariencia es un desarrollo que apuntaría al objetivo de una forma definitiva. Por eso es que el clavel parece más ilustrativo aún de lo que sería la relación cercana entre psicosis paranoica y personalidad: una personalidad es siempre un clavel prolífero, puesto que este, "en su cáliz bien formado y en su corola perfecta, en un receptáculo situado efectivamente en el centro del círculo de los pétalos, vemos desarrollarse yemas que presentan ramas y flores verdaderas y propias" (28); en otros términos, incluso una personalidad lograda podría seguir demostrándonos cómo las metamorfosis del lenguaje, observables en las psicosis, pueden continuar su camino rizomático independiente del árbol logrado que, tal vez sin saberlo, lo alberga. La metáfora nos muestra la presencia de lo que se esconde o de lo que habitualmente está escondido en la planta regular, así como del lado de la rosa prolífera de una psicosis notamos que el lenguaje sigue hablando por sí solo, rompiendo, en efecto, con las formas clásicas 
de la lengua. Pero entonces, ¿cómo entender la modulación de esta palabra que permite que no siempre sea escuchada en su insistente transmisión? La botánica en este caso nos enseña cómo las psicosis paranoicas muestran la relevancia en la formación del Yo y de por qué en este efectivamente se trata de una cuestión de forma, tal y como la pronta elaboración del estadio del espejo vendrá a demostrar. De este modo, una cita del seminario sobre "Las psicosis" - dictado más de 20 años después de la tesis sobre el caso Aimée- se clarifica poniéndola en relación con este asunto:

Se trata para el hombre justamente de arreglárselas con esa modulación continua, como para que no le ocupe demasiado. Por eso mismo, las cosas están arregladas de manera que su conciencia se aparte de ellas. Solo que admitir la existencia del inconsciente, significa decir que aunque su conciencia se desvíe de ella, la modulación de la que hablo, la frase con toda su complejidad, continúa de todos modos [...] Ya que se buscan las funciones del yo en cuanto tal, digamos que una de sus ocupaciones es precisamente no dejarse dar la lata por esa frase que no para nunca de circular, y que no pide otra cosa que volver a surgir bajo mil formas más o menos camufladas y molestas [...] En los fenómenos, llamémoslos provisionalmente teratológicos, de las psicosis, esto opera a cielo abierto. (164)

El yo sería así una flor que detiene el crecimiento, aun cuando la metamorfosis de la palabra, sirviéndose del lenguaje, siga de manera continua expresándose por otras vías. La otra instancia que podemos entender desde ya como aquello que puede modular el "zafarrancho" ("Las psicosis" 419) del significante -el que puede siempre continuar por sí solo su camino- es el del Nombre-del-Padre.

Aún podemos extraer algo más antes de finalizar: si bien Goethe cree comprobar, tanto con la rosa como con el clavel proliferantes, la regla de que la flor logra detener el crecimiento, de nuestra parte podemos decir que las psicosis paranoicas son de por sí algo logrado o que dan cuenta de una misma y única estructura respecto a la personalidad normal. No solo el fenómeno elemental será idéntico al delirio en cuanto a fuerza estructurante, 
sino que es esa misma fuerza la que configuraría tanto a la interpretación razonante como al pensamiento normal. Es en este punto donde tanto la rosa como el clavel demuestran exactamente la misma estructura. Así, podemos concluir doblemente considerando algunas afirmaciones de Lacan en 1976 que i) la misma ley afecta tanto a la llamada personalidad normal como a la psicosis paranoica: el hombre está habitado por el lenguaje, es hablado por este, es el cáncer o el parásito que lo habita (Lacan, El Sinthome 7-8); ii) la psicosis paranoica y personalidad no tienen en rigor relación puesto que son lo mismo (El Sinthome 10). 


\section{Bibliografía}

Baños Orellana, Jorge. La novela de Lacan. Buenos Aires: El Cuenco de Plata, 2013

_. "Las novelas que nos contamos de Lacan". Inconsciente e historia después de Freud. Cruces entre filosofía, psicoanálisis e historiografía. Editado por Omar Acha y Mauro Vallejo. Buenos Aires: Prometeo, 2010, pp. 167-86.

Cassirer, Ernst. "Goethe y la filosofía kantiana". Rousseau, Kant, Goethe. Filosofía y cultura en la Europa del Siglo de las Luces. Madrid: FCE, 2007, pp. 233-79.

Desbordes, Jean. Goethe et la psychanalyse. París: Editions EAO, 1973.

Freud, Sigmund. "Presentación autobiográfica". Obras completas, vol. 20. Buenos Aires: Amorrortu, 2003.

Goethe, Johann Wolfgang. "De l'existence d'un os intermaxillaire ala machoire supérieure de l'homme comme a celle des animaux" (1786). Oenvres d'histoire naturelle de Goethe comprenant divers mémoires d'anatomie comparée, de botanique et de géologie. Traducción y notas de Ch. Fr. Martins. París: Ab. Cherbuliez et Ce, Libraires, 1837, pp. 79-93.

_. "La metamorfosis de las plantas". Teoría de la naturaleza, Madrid: Tecnos, 1997, pp. 13-32.

_. "Leçons sur les trois premiers chapitres de l'introduction a l'étude de l'anatomie comparée basée sur l'ostéologie" (1796). Oeuvres d'histoire naturelle de Goethe comprenant divers mémoires d'anatomie comparée, de botanique et de géologie. Traducción y notas de Ch. Fr. Martins. París: Ab. Cherbuliez et Ce, Libraires. 1837, 61-78.

_. $\quad$ Teoría de la naturaleza, Madrid: Tecnos, 1997.

Gould, Stephen Jay. Ocho cerditos: reflexiones sobre historia natural. Barcelona: Crítica, 1994.

Jones, Ernest. Sigmund Freud: Life and Work. Vol 1: The Young Freud 1856-1900. Londres: Hogarth Press, 1953.

Lacan, Jacques. De la psicosis paranoica en sus relaciones con la personalidad. México D. F.: Siglo XXI, 2010.

_. El sinthome, seminario 23, 1975-1976, clases del 16 de diciembre de 1975 y 17 de febrero de 1976. Establecimiento del texto, traducción y notas Ricardo 
Rodríguez Ponte, para circulación interna de la Escuela Freudiana de Buenos Aires, 2001.

_. Estructura de las psicosis paranoicas. Traducción y presentación de Juan Bauzá. París: s. f.

_. $\quad$ "Las psicosis". El seminario-libro 3. Buenos Aires: Paidós, 2012.

Market, Oswaldo y Jacinto Rivera de Rosales. El inicio del idealismo alemán. Madrid: Editorial Complutense, 1996.

Ochoa, Carlos y Ana Rosa Barahona. Forma versus función. Historia de la homología y la analogía. México: UNAM, 2009.

Richards, Robert J. The Romantic Conception of Life: Science and Philosophy in the Age of Goethe. Chicago y Londres: The University of Chicago Press, 2002.

White, Hayden. Metahistoria. La imaginación histórica en la Europa del siglo XIX. México: FCE, 1992. 